\title{
Toll-like receptor 4 blockade protects kidneys against ischemia- reperfusion injury
}

\author{
Won-Hee Cho, Jung-Woo Seo, Seon Hwa Park, Yang Gyun Kim, Ju-Young Moon, Sang-Ho Lee
}

Department of Internal Medicine-Nephrology, Kyung Hee University Hospital at Gangdong, Korea

Background: Renal ischemia-reperfusion injury (IRI) is involved in the majority of clinical conditions manifested as deteriorated kidney function, however, specific treatment for this type of injury is still far from clinical use. Although animal studies have demonstrated that toll-like receptor 4 (TLR4) is a key mediator of IRI, few evaluation of pharmacological TLR4 inhibition in renal IRI has been carried out.

Methods: We subjected C57BL/6 mice to 23 minutes of renal pedicle clamping preceded by an intraperitoneal injection with vehicle or a TLR4 inhibitor, TLR-inhibitory peptide 1 (TIP1). Sham control mice underwent only a flank incision. The kidneys were harvested after 24 hours of reperfusion for histology, western blot analysis, RT-PCR, and flow cytometry.

Results: Pretreatment with TIP1 lowered the magnitude of elevated serum creatinine levels and attenuated tubular injury. In addition, TIP1 administration led to the reduced mRNA expression of inflammatory cytokines and decreased apoptotic cells as well as lower oxidative stress in postischemic kidneys. In the kidneys pretreated with TIP1, macrophage and T helper 17 cell infiltrations were less abundant compared with IRI only group.

Conclusions: Our data demonstrated that inhibition of TLR4 with TIP1 reduced tubular injury and the inflammatory and immune response in the mouse model of renal IRI.

Corresponding author: Sang-Ho Lee

E-mail: minime12@hanmail.net

(C) The Korean Society for Transplantation

This is an Open Access article distributed under the terms of the Creative Commons Attribution Non-Commercial License (http://creativecommons.org/licenses/by-nc/4.0/) which permits unrestricted non-commercial use, distribution, and reproduction in any medium, provided the original work is properly cited. 